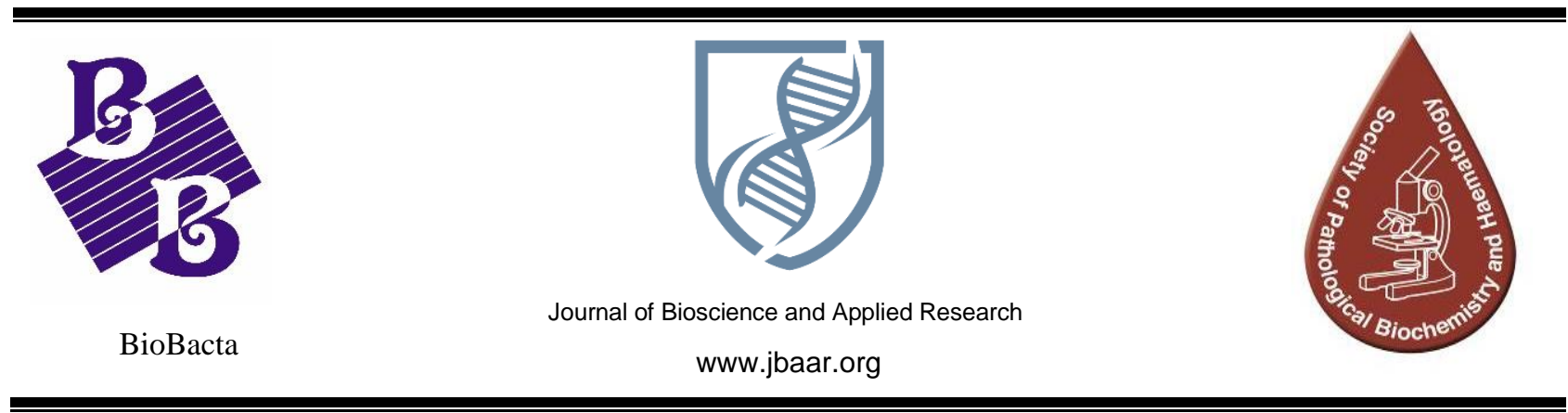

\title{
Annexin V and CXCR4 Expression in Adult Immune Thrombocytopenia. Control Randomized Study.
}

\section{(Annexin in ITP)}

\author{
Rania M fawzy ${ }^{1}$, Amal S Nasr¹, Noha M. El Husseiny ${ }^{2 *}$, Mona Gamil'2, Heba H. El \\ Demellawy $^{3}$, Hend M Hassan ${ }^{1}$, Ibrahim A. Ibrahim ${ }^{2}$ \\ 1 Clinical Pathology Department - Faculty of Medicine-Cairo University- Egypt. \\ 2-Internal medicine Department - Faculty of Medicine- Cairo University- Egypt. \\ 3 Internal Medicine Department- Faculty of Medicine-Beni-Sweif University- Egypt \\ *Correspondence: noha_el_husseiny77@yahoo.com
}

\section{Abstract}

DOI: 10.21608/jbaar.2018.155724

Background: Annexin V is a cellular protein used to detect apoptotic cells by its ability to bind to phosphatidylserine, a marker of apoptosis when it is on the outer leaflet of the plasma membrane.CXCR4 is expressed on cells of megakaryocytic series, especially platelets, and plays an important role in megakaryopoiesis. Both were used to study the pathogenesis of ITP in children. This study aimed to evaluate Annexin V as a marker of early apoptosis and the CXCR4 expression as a marker of megakaryopoiesis in adult patients with ITP. Patients and methods: This study was conducted on 60 patients with ITP with a mean age of $39.23 \pm 12.49$ and 40 healthy subjects with a mean age $36.08 \pm 9.4$ as a control group. Using flow cytometry, we investigated apoptotic markers of platelets annexin $\mathrm{V}$ and megakaryopoiesis marker CXCR4 expression. Results: The percentage of the platelet with early apoptosis-positive markers (Annexin -D1) were less frequent in the ITP group compared to the control group $(\mathrm{p}<0.001)$, the percentage of the platelet with late apoptosispositive markers (Annexin -D2), living platelet (Annexin-D3), necrotic platelet (Annexin-D4) were more frequent in the ITP group compared to the control group $(\mathrm{p}=0.62, \mathrm{p}<0.001, \mathrm{p}=0.016)$ respectively. The percentage of the platelets with CXCR4 expression was lower in ITP patients compared to the controls ( $\mathrm{p}<0.001)$. Conclusion: pathogenesis of ITP in adults is complicated. Platelet Annexin V together with CXCR4 expression may detect apoptosis resistance in adult patients with ITP.

\section{Keywords}

Immune thrombocytopenic purpura (ITP), Annexin V, Chemokine Receptor type 4 (CXCR4).

\section{Introduction}

Immune thrombocytopenia (ITP) is an autoimmune disorder characterized by a peripheral blood count of less than $100 \times 10^{9} / \mathrm{L}(\mathbf{1})$. The most serious complication of thrombocytopenia is intracranial hemorrhage $(\mathbf{2}, \mathbf{3})$. Primary ITP constitutes $80 \%$ of diagnosed patients (4), after excluding drugs, autoimmune diseases, and viral infections as the second cause of thrombocytopenia (5-7). Both increased platelet destruction and reduced production are responsible for the disease (8). 
Glycoprotein IIb /IIIa and their destruction by macrophages or cytotoxic $\mathrm{T}$ cells are the main pathogenic mechanism of ITP. This is aggravated by the associated megakaryocytic dysfunction and reduced thrombopoietin production $(\mathbf{9 , 1 0 )}$. Both platelets, and megakaryocytes, have functional pathways of programmed cell death that were found to be abnormally enhanced in ITP (11-13). Externalization of phosphatidylserine (PS) on the surface of cells undergoing apoptosis is needed for recognition of unwanted self to be cleared by phagocytes, followed by loss of membrane integrity with eventually cellular apoptosis or necrosis $(\mathbf{1 4 , 1 5 )}$. Increased PS exposure was reported in adult patients with chronic ITP (16). Annexin V has a high affinity for PS. Staining with Annexin V is typically used in conjunction with a vital dye such as propidium iodide (PI) for different stages of apoptosis (17-19). A chemokine receptor for stromal cell-derived factor (SDF-1) is present on the surface of both megakaryocytic lineage and the platelet membrane known as Chemokine Receptor type 4 (CXCR4) (20-22). CXCR4/SDF-1 axis plays an important role in platelet production. (23,24) This axis also activates many intracellular signals including increases in $\mathrm{Ca}^{2+}$ influx, activation of phosphatidylinositol 3-kinase, and Akt activation (25-27). Akt activation leads to apoptosis resistance (28). So this axis contributes to the regulation of both physiological pathological processes.

This study aims to evaluate Annexin V and CXCR4 expression in adult ITP to understand the pathogenesis of ITP in adults and to study their utility as predictors of disease chronicity.

\section{Subjects and methods}

This study was approved by the Research Ethical Committee of Kasr Al Aini in Dec 2015. All subjects who participated in the study gave their written consents. This study was conducted on 60 patients with ITP. Twenty-nine(48.3\%) were males and $31(51.7 \%)$ were females with a mean age $39.23 \pm 12.49$ and 40 healthy subjects; 20 (50\%) males and 20 (50\%) females with a mean age $36.08 \pm 9.4$ years as a control group.

All subjects were recruited from the Hematology outpatient clinic- Cairo University.

Patients were subjected to history taking including the severity of the bleeding and need for platelet transfusion, history of drug therapy, and splenectomy. Detailed clinical examination, and laboratory investigation including $\mathrm{CBC}$, liver function tests, bleeding, and coagulation profile. Exclusion criteria were other hematological diseases, Hepatitis C virus, HIV, recent viral infection, Helicobacter infection, autoimmune diseases as SLE, antiphospholipid syndrome, allergy, and liver disease.

Methods: Flow cytometry for platelet Annexin V and CXCR4 (CD184). FITC Annexin V apoptosis detection kit provided by BD pharmingen TM (catalog number 556547). Monoclonal CD184 (CXCR4 - PE) antibodies provided by Miltenyi Biotec: catalog number (130-098-354), clone 12G5 (isotype: mouse IgG2a). Staining with Annexin V is typically used in conjunction with propidium iodide (PI) for the identification of early and late apoptotic cells. Intact membranes exclude PI, whereas the membranes of dead and damaged cells are permeable to PI. Viable cells with intact membranes exclude PI. Therefore, cells considered viable are both Annexin V and PI negative, while cells that are in early apoptosis are Annexin V positive and PI negative, and cells that are in late apoptosis or already dead are both Annexin V and PI positive. All samples were analyzed on a colter EPICS profile II flow cytometry. Results were expressed as a percentage of early apoptotic cells, late apoptotic cells, living cells, and necrotic cells within the gated population. For CXCR4, results were expressed as a percentage of platelets expressing CXCR4 (CD184) within the gated population.

\section{Statistical analysis}

Data were analyzed using the SPSS (ver. 15). Data are presented as median values and ranges. Comparison between quantitative variables was done using the student $t$-test. All tests were twotailed and considered significant at $p<0.05$ and highly significant at $p<0.001$. The relationship between the 2 variables was assessed using Pearson Correlation. A probability value of $\mathrm{P}<0.05$ was 
considered statistically significant.

\section{Results:}

This study included 60 patients with immune thrombocytopenic purpura, forty-six $(76.7 \%)$ of them were chronic and $14(22.3 \%)$ were recently discovered to have the disease.

Steroids were the main therapy for 58 (96.7\%) of the patients, only $10(16.6 \%)$ patients had platelet transfusion and other immunosuppressive medications. Forty healthy subjects were enrolled in the study as a control group. Table 1 demonstrates a comparison between patients and control in demographic and laboratory parameters. Patients and control were age and sex-matched.

There was a highly significant difference between the two groups as regards the HB, HCT, and platelet count $(\mathrm{p}<0.001)$.

Table (2) demonstrates a comparison of the Percentage of Annexin V and CXCR4 expression in the studied groups.

The percentage of the platelet with early apoptosispositive markers (Annexin-D1) was less frequent in the ITP group compared to the control group $(p<0.001)$. However, living platelet (Annexin-D3), necrotic platelet (Annexin-D4) were more frequent in the ITP group compared to the control group $(\mathrm{p}<0.001, \mathrm{p}=0.016)$ respectively. The percentage of the platelet with late apoptosis-positive markers (Annexin-D2) were not statistically different between cases and control $(\mathrm{p}=0.062)$

The percentage of the platelets with CXCR4 expression was lower in chronic ITP patients compared to the controls $(\mathrm{p}<0.001)$.

No significant difference in the percentage of the platelet with positive Annexin or CXCR4 expression between males and females in both groups was found. Also, no significant difference was found in the percentage of the platelet with positive Annexin or CXCR4 expression between chronic and recently discovered patients ( $p>0.05)$. There was a significant positive correlation between $\mathrm{HB}$ and platelet count in the ITP group ( $\mathrm{r}=0.604$, $\mathrm{p}<0.001)$.

\section{Discussion}

The most accepted theory for platelet destruction in ITP is antibody-mediated in the activated reticuloendothelial system (29-31). Previous studies on Annexin V and CXCR4 involved children with ITP. This study concerned adult ITP in whom the pathogenesis and fate are complex as we concluded in a previous publication where we found a great role of $\mathrm{T}$ cells in the pathogenesis of ITP development and impact of steroid treatment on the levels of cytokines release in these cases (32).

In this study, twenty-nine of our patients with ITP were males $(48.3 \%)$ and thirty-one were females $(51.7 \%)$ with age ranged from 19-61(mean age $39.23 \pm 12.49$ ), this is in agreement with Silverman et al. who stated that the peak prevalence of ITP in adults ranges between 20-50 years with a female to male ratio 2.6:1(33).

In this study, the percentage of the platelet with early apoptosis-positive markers (Annexin -D1) was less frequent in the ITP group compared to the control group with a highly significant difference $(\mathrm{p}<0.001)$. In another study, thrombocytopenia induced by antiplatelet antibodies was associated with increased apoptotic markers (30). This difference could be due to that most of our patients were chronic, not acute cases.

However, in another study on children with ITP, no difference in the platelet percentage that became Annexin $\mathrm{V}$ positive between the patients with pediatric chronic ITP and the controls $(\mathrm{P}=0.05)$. (34) They also found that the remaining studied platelets in circulation were apoptotic resistant with the previous destruction of the non-resistant platelets. They found that antibody-mediated platelet destruction via apoptotic pathway mainly occurs in the acute form of ITP. [35]

These findings are concomitant with our observations in adult ITP patients as most of them were chronic. And this was confirmed by the percentage of the platelet with late apoptosispositive markers (Annexin-D2), living platelet (Annexin-D3), necrotic platelet (Annexin-D4) were more frequent in the ITP group compared to the control group $(\mathrm{p}=0.062, \mathrm{p}<0.001, \quad \mathrm{p}=0.016)$ respectively. 
The platelets with CXCR4 expression were lower in chronic ITP patients compared to the controls with a highly significant difference $(p<0.001)$. This is contrary to Wang et al., who found increased CXCR4 expression on platelets in children with chronic ITP and they explained this by the SDF1CXCR4 interaction triggering many intracellular signals related to platelet apoptosis resistance in chronic ITP patients (34). In this study, the decrease in platelet apoptosis might be responsible for the reduced CXCR4 platelet expression. Also, CXCR4 platelet expression is up-regulated by cytokines, including IL-2, IL-4, IL-6, and TGF- $\beta$, and downregulated by INF- $\gamma$ and SDF-1(34,35), these cytokines may be altered by the steroids which were the main line of treatment to our patient thus subsequently decreased the CXCR4 platelet expression.

\section{Conclusion}

Platelet Annexin V might be used as a marker of early apoptosis and together with CXCR4 expression may detect apoptosis resistance in adult patients with ITP. Due to the unpredictable course of ITP in adult patients and the possibility of its progress to refractory form, accurate choice of a biomarker is essential for evaluating prognosis, and detection of resistant forms is required.

\section{Conflict of interest}

The authors declare no conflict of interest.

\section{Financial support and sponsorship}

No funding resources to declare.

\section{References}

1. Provan D, Stasi R, Newland AC, et al. International consensus report on the investigation and management of primary immune thrombocytopenia. Blood. 2010;115:168-186.

2. Lambert MP, Gernsheimer TB. Clinical updates in adult immune thrombocytopenia (ITP). Blood. 2017;129;(21):2829-2835.

3. Abadi U, Yarchovsky-Dolberg O, Ellis $\quad \mathrm{MH}$ Immune thrombocytopenia: recent progress in pathophysiology and treatment. Clin
Appl Thromb Hemost. 2015;21:397404.

4. Imbach P, Crowther $\mathrm{M}$. Thrombopoietin- receptor agonists for primary immune thrombocytopenia. N Engl J Med. 2011;365;(8): 734-741.

5. Reese JA, Li X, Hauben M, et al. Identifying drugs that cause thrombocytopenia: an analysis using three distinct methods. Blood. 2010;116;(8):2127-2133.

6. Neunert C, Lim W, Crowther M, et al. The American Society of Hematology 2011 evidence-based practice guidelines for immune thrombocytopenia. Blood. 2011;117:4190-4207.

7. Cecinati V, Principi N, Brescia L, et al. Vaccine administration and the development of immune thrombocytopenic purpura in children. Hum Vaccin Immunother. 2013;9;(5):1158-1162.

8. Nugent D, McMillan R, Nichol JL, et al. Pathogenesis of chronic immune thrombocytopenia: increased platelet destruction and/or decreased platelet production. $\mathrm{Br} \quad \mathrm{J}$ Haematol. 2009;146:585-596.

9. Godeau B. Immune thrombocytopenic purpura: major progress in knowledge of the pathophysiology and the therapeutic strategy, but still a lot of issues. Presse Med. 2014;43(4 pt 2):e47e48.

10. Tripathi AK, Mishra S, Kumar A, et al. Megakaryocyte morphology and its impact in predicting response to steroid in immune thrombocytopenia. Platelets. 2014;25;(7):526-531.

11. Leytin V. Apoptosis in the anucleate platelet. Blood Rev. 2012;26:51-63. 
12. White MJ, Kile BT. Apoptotic processes in megakaryocytes and platelets. Semin Hematol. 2010;47: 227-234.

13. Houwerzijl EJ, Blom NR, Van der Want JL, et al.. Megakaryocytic dysfunction in myelodysplastic syndromes and idiopathic thrombocytopenic purpura is in part due to different forms of cell death. Leukemia. 2006;20:1937-42.

14. Savill J, Fadok V. Corpse clearance defines the meaning of cell death. Nature. 2000;407:784-8.

15. Erwig LP, Henson PM. Clearance of apoptotic cells by phagocytes. Cell Death Differ. 2008;15:243-50.

16. Catani L, Fagioli ME, Tazzari PL, et al. Dendritic cells of immune thrombocytopenic purpura (ITP) show increased capacity to present apoptotic platelets to T lymphocytes. Exp Hematol. 2006;34:879-87.

17. Casciola-Rosen L, Rosen A, Petri M, et al,. Surface blebs on apoptotic cells are sites of enhanced procoagulant activity: implications for coagulation events and antigenic spread in systemic lupus erythematosus. Proc Nat Acad Sci USA. 1996;93:16241629.

18. Van Engeland M, Ramaekers FC, Schutte B, et al. A novel assay to measure loss of plasma membrane asymmetry during apoptosis of adherent cells in culture. Cytometry. 1996;24:131-139.

19. Vermes I, Haanen C, SteffensNakken $\mathrm{H}$, et al. A novel assay for apoptosis.:Flow cytometric detection of phosphatidylserine expression on early apoptotic cells using fluorescein-labeled Annexin V. J Immunol Methods. 1995;184:39-51.

20. Kowalska MA, Ratajczak J, Hoxie J, et al. Megakaryocyte precursors, megakaryocytes, and platelets express the HIV co-receptor CXCR4 on their surface: determination of response to stromal-derived factor-1 by megakaryocytes and platelets. $\mathrm{Br}$ J Haematol. 1999;104:220-9.

21. Riviere C, Subra F, Cohen-Solal K, et al. Phenotypic and functional evidence for the expression of CXCR4 receptor during megakaryocytopoiesis.

Blood.1999;93:1511-23.

22. Wang JF, Liu ZY, Groopman JE. The alpha-chemokine receptor CXCR4 is expressed on the megakaryocytic lineage from progenitor to platelets and modulates migration and adhesion. Blood. 1998;92:756-64.

23. Hamada T, Mohle R, Hesselgesser J, et al. Transendothelial migration of megakaryocytes in response to stromal cell-derived factor 1 (SDF-1) enhances platelet formation. J Exp Med. 1998;188:539-48.

24. Guerriero R, Mattia G, Testa U, et al. Stromal cell-derived factor 1 alpha increases polyploidization of megakaryocytes generated by human hematopoietic progenitor cells. Blood. 2001;97:2587-95.

25. Ganju RK, Brubaker SA, Meyer J, et al. The alpha-chemokine, stromal cell-derived factor-1 alpha, binds to the transmembrane G-proteincoupled CXCR-4 receptor and activates multiple signal transduction pathways. J Biol Chem. 1998;273:23169-75.

26. Sotsios Y, Whittaker GC, Westwick $\mathrm{J}$, et al. The CXC chemokine stromal cell-derived factor activates a G(i)Coupled phosphoinositide 3-kinase in $\mathrm{T}$ lymphocytes. $\mathrm{J}$ Immunol. 1999;163:5954-63.

27. Majka M, Ratajczak J, Kowalska $\mathrm{MA}$, et al. Binding of stromal- 
derived factor-1 alpha (SDF-1 alpha)

to CXCR4 chemokine receptor in normal human megakaryoblasts but not in platelets induces phosphorylation of mitogenactivated protein kinase p42/44 (MAPK), ELK-1 transcription factor, and serine/ threonine kinase Akt. Eur J Haematol. 2000;64:164-72.

28. Vlahakis SR, Villasis-Keever A, Gomez T, et al. G protein-coupled chemokine receptors induce both survival and apoptotic signaling pathways. $\mathrm{J}$ Immunol. 2002;169:5546-54.

29. McMillan R. Autoantibodies and autoantigens in chronic immune thrombocytopenic purpura. Semin Hematol. 2000;37:239-48.

30. Nieswandt B, Bergmeier W, Rackebrandt K, et al. Identification of critical antigen-specific mechanisms in the development of immune thrombocytopenic purpura in mice. Blood. 2000;96:2520-7.

31. Leytin V, Mykhaylov S, Starkey AF, et al. Intravenous immunoglobulin inhibits anti-glycoprotein IIbinduced platelet apoptosis in a murine model of immune thrombocytopenia. Br J Haematol. 2006;133:78-82.
32. Noha M. El Husseiny, Amira El Sobky, Ahmed M. Khalaf, Mohamed Fateen, Doaa M. El Demerdash, Heba Youssef, Marwa Salah, Sara El Sayed Abd El Ghany, Sherin El Husseiny, and Mona Gamil. Chronic immune thrombocytopenia. Egyptian experience. Comparative clinical pathology. DOI: 10.1007/s00580018-2659-8.published online 13 Feb.2018

33. Silver MA. Immune thrombocytopenia. Pathogenesis and treatment approaches. J.haem.trans. 2016; 5:1056-1065.

34. Wang JD, Ou TT, Wang CJ, et al. Platelet apoptosis resistance and increased CXCR4 expression in pediatric patients with chronic immune thrombocytopenic purpura. Thrombosis Research. 2010; 126: 311-318.

35. Buckley CD, Amft N, Bradfield PF, et al. Persistent induction of the chemokine receptor

CXCR 4 by TGF-beta 1 on synovial $\mathrm{T}$ cells contributes to their accumulation within the rheumatoid synovium. J Immunol. 2000;165:3423-9. 
Table (1) Demographic and Laboratory data of patients group and control group.

\begin{tabular}{|l|c|c|c|c|c|}
\hline & \multicolumn{2}{|c|}{$\begin{array}{c}\text { Patients } \\
\text { (n=60) }\end{array}$} & \multicolumn{2}{c|}{$\begin{array}{c}\text { Control } \\
(\mathbf{n}=40)\end{array}$} \\
\cline { 2 - 5 } & Mean \pm SD & Range & Mean \pm SD & Range & \\
\hline Age (years) & $39.23 \pm 12.49$ & $19-61$ & $36.08 \pm 9.45$ & $21-56$ & 0.177 \\
\hline Male & $29(48.3 \%)$ & & $20(50 \%)$ & & \multirow{2}{*}{0.870} \\
\hline Females & $31(51.7 \%)$ & & $20(50 \%)$ & & $<0.001$ \\
\hline HB gm/dl & $11.51 \pm 1.5$ & $8.6-14.7$ & $12.72 \pm 1.13$ & $11-14.7$ & $<0.001$ \\
\hline Ht (\%) & $34.72 \pm 3.998$ & $27.3-43.8$ & $38.1 \pm 2.92$ & $30.9-44.1$ & 0.008 \\
\hline RBCs (x10/L) & $4.16 \pm 0.62$ & $2.5-5.7$ & $4.48 \pm 0.51$ & $3.6-5.7$ & 0.644 \\
\hline MCV (f1) & $84.76 \pm 9.85$ & $65.7-117$ & $85.57 \pm 6.04$ & $70-98$ & 0.616 \\
\hline MHC (pg) & $28.21 \pm 4.25$ & $18.8-41.4$ & $28.57 \pm 2.22$ & $22.4-32.6$ & 0.553 \\
\hline TLC (x103/L) & $6.92 \pm 2.22$ & $4-14$ & $6.68 \pm 1.48$ & $4-9$ & $<0.001$ \\
\hline PLTs (x103/L) & 50.5 & $9-127$ & 266.5 & $190-330$ & \\
\hline
\end{tabular}

( $\mathrm{HB}=$ Hemoglobin, $\mathrm{Ht}=$ hematocrits, $\mathrm{RBCs}$, red blood cells, $\mathrm{MCV}=$ means cell volume, $\mathrm{MHC}=$ means corpuscular hemoglobin, TLC $=$ total leucocytes count, PLTs= platelets number, \#=median)

Table (2) Percentage of Annexin V and CXCR4 expression in the studied groups.

\begin{tabular}{|l|c|c|c|c|c|}
\hline & \multicolumn{2}{|c|}{$\begin{array}{c}\text { patients } \\
\text { (no=60) }\end{array}$} & \multicolumn{2}{c|}{$\begin{array}{c}\text { Control } \\
\text { (no=40) }\end{array}$} & p value \\
\cline { 2 - 6 } & median & Range & median & Range & \\
\hline Annexin-D1 \% & 0.085 & $0.00-2.48$ & 1.20 & $0.00-5.76$ & $<0.001$ \\
\hline Annexin-D2 \% & 0.00 & $0.00-0.63$ & 0.00 & $0.00-0.12$ & 0.062 \\
\hline Annexin-D3 \% & 99.8 & $98-100$ & 98.8 & $94-100$ & $<0.001$ \\
\hline $\begin{array}{l}\text { Annexin-D4 } \\
\text { \% }\end{array}$ & 0.07 & $0.00-2$ & 0.00 & $0-0$ & 0.016 \\
\hline CXCR4 \% & 0.42 & $0.07-5.59$ & 1.4 & $0.07-36.8$ & $<0.001$ \\
\hline
\end{tabular}

(Annexin -D1= early apoptotic cells, Annexin-D2= late apoptotic cells, Annexin-D3= living cells, AnnexinD4=necrotic cells, CXCR4= Chemokine Receptor type 4.) 